\title{
Impaired leptin activity in New Zealand Obese mice: model of angiogenesis
}

\author{
Lukasz Wator · Urszula Razny · Adriana Balwierz • \\ Anna Polus · Hans G. Joost · Grzegorz Dyduch • \\ Romana Tomaszewska $\cdot$ Aldona Dembinska-Kiec
}

Received: 8 October 2008/Accepted: 12 November 2008/Published online: 26 November 2008

(C) Springer-Verlag 2008

\begin{abstract}
Leptin is prompt to drive angiogenesis, effecting proper vascularisation. Tissue remodeling (including adipose organ) is associated with the angiogenic response. The aim of this study was to investigate the effect of hyperleptinemia on angiogenesis in subcutaneous (s.c.) in vivo matrigel model in mice on a high fat (HF) diet. HF promoted adipose tissue accumulation and biochemical changes resembling metabolic syndrome. However, the impact of this dietary treatment on angiogenesis, measured in s.c. matrigel model was not significant. Changes in leptin concentration were not accompanied by significant angiogenic response. This lack of leptin activity and impaired signal transduction at the molecular level suggests malfunction of the leptin receptor in NZO mice.
\end{abstract}

Keywords CD31 PECAM1 - Leptin - Leptin receptor · NZO $\cdot$ Obesity

L. Wator $(\bowtie) \cdot$ U. Razny · A. Balwierz · A. Polus ·

A. Dembinska-Kiec

Department of Clinical Biochemistry, Jagiellonian University

Medical College, Kopernika 15a, 31-501 Cracow, Poland

e-mail: 1wator@cm-uj.krakow.pl

A. Dembinska-Kiec

e-mail: mbkiec@cyf-kr.edu.pl

G. Dyduch · R. Tomaszewska

Department of Pathomorphology, Jagiellonian University

Medical College, Cracow, Poland

H. G. Joost

German Institute of Human Nutrition,

Potsdam-Rehbrücke, Germany

\section{Introduction}

Angiogenesis is crucial for organ development as well as for tumor growth [3]. Pathological angiogenesis associates diabetic retinopathy, which is a major cause of blindness related to diabetes and metabolic syndrome (MS) complications [13, 15].

Adipokines, secreted by adipose tissue, are important for the angiogenic response. Leptin was demonstrated to stimulate angiogenesis through expression of the vascular endothelium growth factor (VEGF) receptors [2], and promotion of progenitor cell differentiation [8]. Adiponectin induces nitric oxide (NO) release and acts protectively towards endothelial cells $[9,14]$. Thus, the decrease of adiponectin level, associating obesity, contributes to the endothelial dysfunction observed in metabolic syndrome [6].

The aim of this study was to verify whether increased hyperleptinemia in obesity modifies the angiogenic effect. To investigate this, the New Zealand Obese (NZO) mice model was used. NZO mice exhibit polygenic syndrome of hyperphagia, obesity, insulin resistance, and hypercholesterolemia [4, 12]. Moreover, $\mathrm{HF}$ diet causes marked elevation of leptin in adipose tissue and serum in these animals [19].

\section{Materials and methods}

This study was approved by the University Ethic Committee (No 58/OP/2003).

Female NZO mice (NZO/H1Bom) were housed in $12 \mathrm{~h} /$ $12 \mathrm{~h}$ daylight cycle with free access to food and water. At the age of 6 weeks, mice were split in two experimental groups: control $(n=11)$ fed with standard diet containing 
$3 \%$ fat (Motycz, Poland) and cases $(n=10)$ fed with HF diet in which $39 \%$ of total energy was derived from coconut oil (SFA) (MP Biomedicals, CA, USA). Feeding lasted for 7 weeks and during that time body mass, chow uptakes as well as fasting concentration of serum glucose, cholesterol, and triglycerides (TG) were monitored.

Leptin, adiponectin, and insulin concentrations were estimated in serum (ELISA) of 13 week-old-mice at the end of the experimental period.

During the last week of the experiment mice received subcutaneous injections of $0.5 \mathrm{ml}$ of matrigel basement (Becton Dickinson, USA) containing $25 \eta \mathrm{mol} / 1$ basic fibroblast growth factor (Sigma-Aldrich, USA). After 6 days, mice were euthanized and matrigel plugs were removed. In the harvested matrigel plugs the angiogenic response, as well as gene expression, were analyzed the invaliding cells $[11,18]$.

To investigate the influence of HF on expression profiles, RNA was isolated and hybridized to Affymetrix 430A_2 GeneChips. The results were analyzed using GeneChip Operating Software (GCOS 1.4). Only genes with significant differences in signal intensity of at least 1.4-fold and $P<0.05$ were included for further analysis. Analysis of regulated pathways was performed using Genmapp and MetaCore softwares.

In order to confirm expression of chosen genes previously indicated in the microarray, quantitative real-time PCR was performed.

Angiogenic response in matrigel plug was estimated by the amount of CD31 (PECAM1)-positive structures and expressed as number of vessels with or without the lumen, as well as number of individual CD31-positive cells.

Results were shown as mean value \pm standard deviation (SD). Number of CD31 positive structures was normalized with a base-2 $\log$ arithm $(\log 2)$. Comparisons of the means were made using the unpaired Student $t$ test. $P<0.05$ was considered statistically significant.

\section{Results}

Animals on the HF diet increased their weight up to $20 \pm 1.9 \mathrm{~g}(110 \%$ of the startup mass), whereas the control group of NZO mice fed with a standard diet gained $11.3 \pm 3.2 \mathrm{~g}$ ( $64 \%$ of their startup mass). Those differences were statistically significant (Table 1). Moreover, the HF diet significantly increased serum glucose and cholesterol levels as well as serum insulin and leptin concentrations (Table 1). All those differences were statistically significant and leptin concentration correlated $(R=0.92)$ with the weight gain (Fig. 1). Triglycerides (TG) and adiponectin levels in blood serum did not differ between groups of animals.
Table 1 Comparison of the area under curve values (glucose, cholesterol), body weight and ELISA measurements (insulin, leptin) between HF diet fed animals (HF) and controls

\begin{tabular}{lcc}
\hline & Standard diet (control) & High fat diet (HF) \\
\hline Glucose (AUC) & $58.43 \pm 4.39$ & $77.73^{* *} \pm 5.09$ \\
Cholesterol (AUC) & $24.04 \pm 3.82$ & $44.87^{* *} \pm 2.27$ \\
End body weight $(\mathrm{g})$ & $31.23 \pm 2.33$ & $38.04^{* *} \pm 3.09$ \\
Insulin [ng/ml] & $0.92 \pm 0.47$ & $2.47^{* *} \pm 1.07$ \\
Leptin [ng/ml] & $18.77 \pm 16.24$ & $73.93^{* *} \pm 11.94$ \\
\hline
\end{tabular}

Mean $\pm \mathrm{SD} ; \quad$ from ST $(n=11), \quad$ HF $\quad(n=10)$; significance $* p<0.05, * * p<0.01$

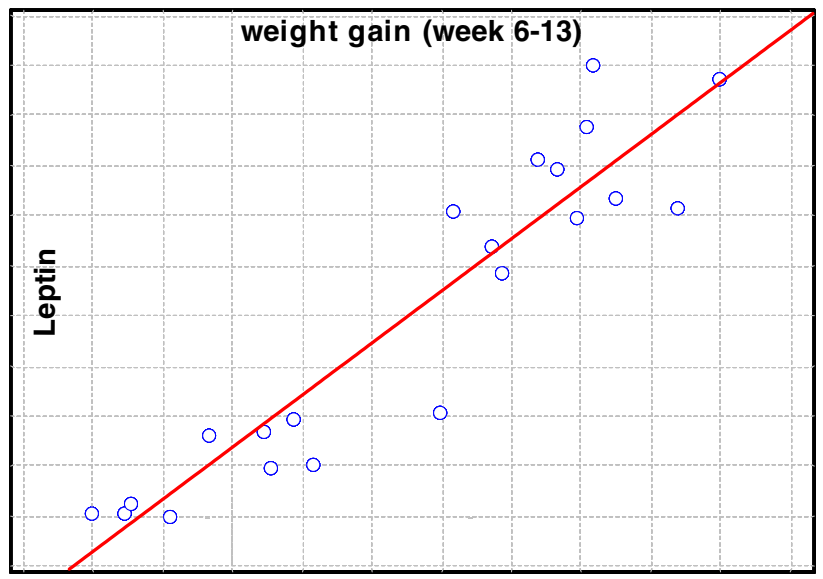

Fig. 1 Spearman Rank-order correlation between leptin concentration and weight gain for NZO mice. $R=0.92 ; n=21 ; p<0.0001$
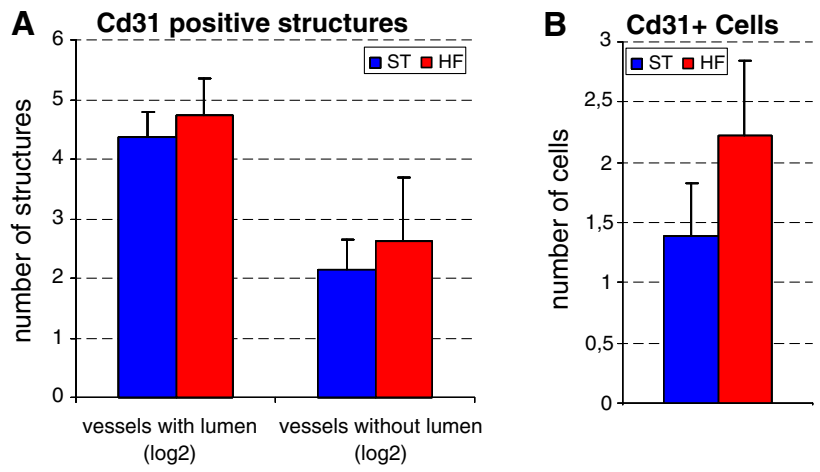

Fig. 2 Comparison of normalized numbers $\mathrm{Cd} 31$ positive structures present in matrigel plug. Mean $\pm \mathrm{SD}$; from ST $(n=10), \operatorname{HF}(n=8)$. Figure 1a Vessels with lumen and vessels without lumen. Figure $1 \mathrm{~b}$ Single Cd31 positive cells

Analysis of angiogenic response in matrigel plugs revealed a tendency towards increased CD31 positive structures in the HF group; however, these results were not statistically significant (Fig. 2).

In order to check for possible effects of hyperleptinemia on the angiogenic process microarray analysis of gene 
expression was performed on cells migrating into matrigel plugs.

High fat diet up-regulated gene expression of numerous growth factors involved in the process of angiogenesis, including VEGFA, epidermal grow factor (EGF), fibroblast growth factors 1/18 (FGF1, FGF18), heparin-binding EGFlike growth factor (HBEGF), platelet derived growth factor alpha (PDGFA). In parallel, the expression of their receptors (Kdr, Flt1 Egfr, Tie1) was inhibited.

High fat diet induced expression of genes involved in the sphingosine 1-phosphate (S1P) signal transduction pathway (Sphk1, Edg1, Akt1, Akt3), as well as of prostaglandin pathway related genes of prostaglandin syntheses (Cox1, Cox2, Ptgis) and prostaglandin receptor (Ptgir).

Gene expression of stromal cell derived factor-1-alpha (Sdf-1-alpha) was inhibited under the HF treatment, and so was its receptor (Cxcr4). Also the JAK-STAT pathway was generally down-regulated in this group of animals.

\section{Discussion}

It has been demonstrated that leptin promotes the angiogenic processes [1, 17]. The weight of NZO mice correlated with leptin concentrations and the animals fed with a HF diet demonstrated hyperleptinemia. This group however, did not present much higher angiogenic potential. Moreover, neither leptin nor adiponectin concentrations correlated with the angiogenic response.

Growth factors such as EGF, FGF1, FGF18, HBEGF, PDGFA, as well as crucial for angiogenesis (VEGFA) were activated, but on the other hand expression of most of their receptors (Kdr, Flt1 Egfr, Tie1) was inhibited. Sdf-1-alpha, which is a major chemotactic chemokine for endothelial progenitor cells, was also down regulated.

On other hand the sphingosine 1-phosphate (S1P) signal transduction pathway, which was found to activate endothelial cell migration [20] was activated. Thus, analysis of gene expression of the above mentioned angiogenic factors do not allow to identify the direction in which this process of vessel formation is driven by a HF diet.

Adipose tissue, stimulated by insulin, is the source of proangiogenic and proinflammatory VEGF, Il-8, and Serpin1 [10]. The present study confirmed the significant increase of biochemical parameters associating insulin resistance in obesity after $\mathrm{HF}$ treatment in NZO mice. Thus, proangiogenic VEGFA gene induction might not be only leptin dependent, and can be up-regulated, due to insulin and/or glucose elevation [16, 21].

Among the observed changes in expression only a few genes were in agreement with leptin related effect. For instance, cyclooxygenase-2 (Cox2) activity was reported to be linked to hyperleptinemia in obesity (Fain 2001); Cox2 drives biosynthesis protective for endothelium prostaglandins (Hink U, 2006). The prostaglandin synthase and prostacyclin receptor were up-regulated in matrigel invading cells.

Down regulation of VEGF receptor and of the JAK-STAT pathway may explain the weak angiogenic response and suggests an impairment of leptin signal transduction in our model. Malfunction of the leptin receptor is found in obesity and a related polymorphism of its gene in NZO mice has been described [5]. However, the role of this polymorphism has never been reported as major origin of hyperphagia in these animals, and its role remained unclear [5, 7]. The results presented in this study imply possible malfunction of the leptin receptor, and therefore impaired angiogenic response in the NZO mice model.

In conclusion, the results obtained in the NZO mice model of obesity suggest that a HF diet promotes adipose tissue accumulation and symptoms similar to human metabolic syndrome. However, the impact on angiogenesis, measured as number of CD31 positive cells migrating into matrigel, as well as gene expression in those cells, do not confirm a pro-angiogenic effect of leptin.

Acknowledgments This study was supported Polish Committee of Science and funded by grants (PBZMIN-005/P04/2002/5) (PBW 2P05A 142 30) and European Nutrigenomic Organization (FP6-2004506360).

Conflict of interest statement There is no conflict of interest to declare.

\section{References}

1. Bouloumie A, Drexler HC, Lafontan M, Busse R (1998) Leptin, the product of $\mathrm{Ob}$ gene, promotes angiogenesis. Circ Res 83:1059-1066

2. Cao R, Brakenhielm E, Wahlestedt C, Thyberg J, Cao Y (2001) Leptin induces vascular permeability and synergistically stimulates angiogenesis with FGF-2 and VEGF. Proc Natl Acad Sci USA 22:6390-6395

3. Ferrara N (2000) Vascular endothelial growth factor and the regulation of angiogenesis. Recent Prog Horm Res 55:15-35 discussion $35-36$

4. Giesen K, Plum L, Kluge R, Ortlepp J, Joost HG (2003) Dietdependent obesity and hypercholesterolemia in the New Zealand obese mouse; identification of a quantitative trait locus for elevated serum cholesterol on the distal mouse chromosome 5 . Biochem Biophys Res Commun 304:812-817

5. Igel M, Becker W, Herberg L, Joost HG (1997) Hyperleptinemia, leptin resistance, and polymorphic leptin receptor in the New Zealand obese mouse. Endocrinology 138:4234-4239

6. Ishioka K, Omachi A, Sagawa M, Shibata H, Honjoh T, Kimura $\mathrm{K}$ et al (2006) Canine adiponectin; cDNA structure, mRNA expression in adipose tissues and reduced plasma levels in obesity. Res Vet Sci 80:127-132

7. Jürgens HS, Schürmann A, Kluge R, Ortmann S, Klaus S, Joost HG, Tschöp MH (2006) Hyperphagia, lower body temperature, 
and reduced running wheel activity precede development of morbid obesity in New Zealand obese mice. Physiol Genomics 25:234-241

8. Laharrague P, Oppert JM, Brousset P, Charlet JP, Campfield A, Fontanilles AM et al (2000) High concentration of leptin stimulates myeloid differentiation from human bone marrow CD34+ progenitors;potential involvement in leukocytosis of obese subjects. Int J Obes Relat Metab Disord 24:1212-1216

9. Lam KS, Xu A (2005) Adiponectin;protection of the endothelium. Curr Diab Rep 5:254-259

10. Mick GJ, Wang X, McCornick K (2002) White adipocyte vascular endothelial growth factor; regulation by insulin. Endocrinology 143:948-953

11. Ohashi K, Yokoyama T, Nakajima Y, Kosovsky M (2004) Methods for implantation of BD Matrigel ${ }^{\mathrm{TM}}$ Matrix into mice and tissue fixation BD Biosciences discovery labware; Tech Bull \#455

12. Ortlepp JR, Kluge R, Giesen K, Plum L, Radke P, Hanrath P et al (2000) A metabolic syndrome of hypertension, hyperinsulinemia, and hypercholesterolemia in the New Zealand obese mouse. Eur J Clin Invest 30:195-202

13. Oshitari T, Hata N, Yamamoto S (2008) Endoplasmic reticulum stress and diabetic retinopathy. Vasc Health Risk Manag 4:115122

14. Ouchi N, Kobayashi H, Kihara S, Kumada M, Sato K, Inoue T, et al (2004) Adiponectin stimulates angiogenesis by promoting cross-talk between AMP-activated protein kinase and Akt signaling in endothelial cells. J Biol Chem 9, 279(2):1304-1309

15. Sanchez-Thorin JC (1998) The epidemiology of diabetes mellitus and diabetic retinopathy. Int Ophthalmol Clin 38:11-18

16. Seo MJ, Oh SJ, Kim SI, Cho KW, Jo I, Schaub T, Schilling H, Passlick-Deetjen J, Han DC (2001) High glucose dialysis solutions increase synthesis of vascular endothelial growth factors by peritoneal vascular endothelial cells. Perit Dial Int 21:S35-S40

17. Sierra-Honigmann MR, Nath AK, Murakami C, Garcia-Cardena G, Papapetropoulos A, Sessa WC et al (1998) Biological action of leptin as an angiogenic factor. Science 281:1683-1686

18. Vecchi A, Garlanda C, Lampugnani MG, Resnati M, Matteucci C, Stoppacciaro C et al (1994) Monoclonal antibodies specific for endothelial cells of mouse blood vessels. Their application in the identification of adult and embryonic endothelium. Eur J Cell Biol 63:247-254

19. Wolever TM (2004) Effect of blood sampling schedule and method of calculating the area under the curve on validity and precision of glycaemic index values. Br J Nutr 91:295-301

20. Young N, Van Brocklyn JR (2006) Signal transduction of sphingosine-1-phosphate $\mathrm{G}$ protein-coupled receptors. Sci World J 11:946-966

21. Zhou Q, Liu LZ, Fu B, Hu X, Shi X, Fang J, Jiang BH (2007) Reactive oxygen species regulate insulin-induced VEGF and HIF-1alpha expression through the activation of p70S6K1 in human prostate cancer cells. Carcinogenesis 28:28-37 